\title{
Women's Decision Making on Birthing Choices in the Private Sector of Namibia: Midwives' Perspectives
}

\author{
Sarah Mlambo \\ https://orcid.org/0000-0001-9282-6165 \\ Stellenbosch University \\ sarahmlambo@yahoo.co.uk \\ Cornelle Young \\ https://orcid.org/0000-0002-9739-1321 \\ Stellenbosch University \\ cornelle@sun.ac.za
}

\author{
Jenna Morgan-Cramer \\ Stellenbosch University \\ jjmorgancramer@gmail.com
}

\section{Abstract}

In this study, the views of midwives regarding decision making in the Namibian private sector hospital labour wards were investigated with the aim of understanding the reasons for the high prevalence of caesarean sections in the Namibian private sector. The study objective was to determine the views of midwives about how women in the private sector labour wards decide on a birthing method. A qualitative design with an exploratory approach was followed, with the application of purposive sampling in the selection of research participants. Seven individual and in-depth interviews with midwives were conducted in two private hospitals in Windhoek. Data analysis was done using the six steps proposed by Creswell. Findings indicated that decision making depended on the woman, the doctor and the institution. Aspects such as the midwife's relationship with the doctor, as well as the pregnant woman and the institution have an influence on such decisions made. Furthermore, the trust among and between health professionals, the availability of policies and guidelines, as well as the information received during antenatal care also affect the choice. It was found that women are not well informed about the choices they have for childbirth, the advantages and disadvantages of the chosen mode of birthing, as well as what to expect during the active stages of labour. In conclusion, decision making in the labour wards is important as it determines the birthing method outcome for every woman in the labour ward. Further studies need to be done in the same context and public hospital settings, to explore the dynamics in the public sector.

\section{UNISA $\cong$}


Keywords: childbirth; decision making; midwife; private sector; qualitative study; birth plan

\section{Introduction and background}

Pregnancy and childbirth are normal and healthy events that most women, couples, and families aspire to experience at some point in their lives. However, this normal and lifeaffirming process might carry serious short and long-term life-threatening risks of death and disability (Sandall et al. 2018, 1349). Every woman has the right to a positive birth experience, with the need for compassionate and individualised care from skilled and knowledgeable healthcare providers (International Federation of Gynaecology and Obstetrics [FIGO] 2014, 95). The International Confederation of Midwives (ICM) $(2017,1)$ states that every woman should have access to care of a high standard from midwives before and during pregnancy, as well as during the actual childbirth and postnatal periods, regardless of their socio-economic status. Furthermore, healthcare providers have a duty to ensure that women receive appropriate information so that they can make informed decisions about the mode of birthing.

According to the Robson classification (Vogel et al. 2015, 260), all deliveries are classified into one of 10 groups based on the five parameters of gestational age, obstetric history, foetal lie, number of neonates, and the onset of labour. Medical staff members are advised to use this system to determine the mode of delivery as a way to ensure that the mother and infant will have a safe delivery. Developments in technology and advanced medical care have increased the prevalence of caesarean sections, a procedure that has been, and continues to be a critical intervention to save the lives of both mother and baby (Coalition for Improving Maternity Services [CIMS] 2010, 1; World Health Organisation [WHO] 2015a 1). However, some hospitals are especially prone to unusually high rates of caesarean sections, and the private sector in Namibia is quoted as one such area (Tjihenuna 2015, 5). Yet the benefits to both the mother and baby can be gained from preventing unnecessary caesarean sections to low risk women (Childbirth Connection 2014, 14), also thus decreasing subsequent deliveries by caesarean sections for the same women.

Compared to the WHO ideal proportion of $10-15 \%$ or less caesarean sections (Appropriate Technology for Birth 1985, 436), the Namibian private sector caesarean section rates reflected an average of $73 \%$ (Namibia Association of Medical Aid Funds [NAMAF] 2015) in 2012, with an upward trend towards 74\% in 2014. This contrasts with the public sector where the Ministry of Health and Social Services (MoHSS) takes pride in the fact that $88 \%$ of women deliver their babies normally, with only $12 \%$ receiving caesarean sections, thus abiding by the WHO recommended levels of 10 to 15\% (MoHSS 2013). The unavailability and or overdependence on caesarean section births reflect poorly on the state of healthcare in any country, indicating either that women do not have access to this procedure when necessary, or that they have it electively, without any medical reason, thus increasing the overall financial burden of healthcare (Gibbons et al. 2010, 3). 
The WHO policy $(2015 \mathrm{a}, 1)$ demands that efforts should be made to ensure that caesarean sections are provided to women in need, rather than to strive to achieve a specific rate. Moreover, the Robson classification identifies the categories in which decisions towards most caesarean sections should fall. In this sense, the Robson classification is there to guide and give information, thus aiming at decreasing the need for inopportune caesarean sections. The Robson classification groups women who present in the maternity unit in one of 10 groups, based on the five characteristics in obstetrics of parity (nulliparous vs multiparity); onset of labour (Induction of Labour vs spontaneous or preterm); number of foetuses (single vs multiple); gestational age (preterm vs term); and foetal presentation (breech vs cephalic). This tool is generally and purposively used retrospectively.

It has to be noted that the Namibian healthcare system has two pillars consisting of the public and the private healthcare sectors, and there is no national health insurance scheme. The private sector works in partnership with medical aid societies, as the medical aid societies pay the private hospitals for the services rendered to patients that subscribe with them. The Government of the Republic of Namibia pays for the services rendered to patients (not completely free as there is a small amount that they pay for obtaining a card/health passport) who do not have a medical aid scheme, and they are treated in the public sector's state hospitals (Brockmeyer 2012, 2).

Moreover, in the Namibian context, pregnant women in the private sector have private medical doctors as the primary care-givers for the antenatal visits, as opposed to the public sector where women have midwives as the primary carers for low risk pregnancies. The midwives in the private sector hospitals have little to no contact with women in the antenatal period as the women go to their doctors for the antenatal visits. A few such private doctors refer women to the small number of private midwives who offer antenatal classes, but this is essentially for these classes only, and not for the routine antenatal healthcare. Thus, not many pregnant women have exposure to private midwives or doulas offering antenatal classes, as these practices are still not established in Namibia.

\section{Statement of the Research Problem}

Namibia has a high rate of $75 \%$ caesarean sections in the private sector, which is causing increasing concern amongst the public, politicians and the government; and this necessitated the present research (NAMAF 2015). Chen et al. $(2018,9)$ argue that women are often pressurised into deciding on a convenient birthing option. This happens at a time when women are vulnerable due to pain and extreme discomfort, not having had enough advice and information about the birthing process, not having enough medical knowledge, and fearing for their unborn infants and their own lives. The midwife, as a third party in the labour ward (where options on alternatives about birthing methods are communicated) can therefore give valuable insights about how these decisions are facilitated. Furthermore, the midwife is an advocate for the women and their unborn infants, and the midwife's role is to give a view on anything that might 
compromise the two patients in this situation. However, there is a paucity of scientific knowledge about the decision-making process in the active labour phase where birthing options can be (re)considered, especially within the Namibian context.

A caesarean section is an effective intervention where medical complications in pregnancy relating to the mother or the foetus arise (WHO 2015b, 1). However, the procedure remains a major operation with serious risk factors for the woman as well as the infant (CIMS 2010, 1). Ultimately, the choice of a birthing method remains the autonomous decision of the individual woman (Shahoei et al. 2013, 302). Private doctors, as customers of private hospitals in Namibia (Tjihenuna 2015, 5), make use of the hospital facilities to deliver their pregnant patients. As a result, in most cases the birthing method is selected primarily by the women on advice from the doctor, simply because of their relationship which dates back to their antenatal visits.

However, midwives are the major care-givers of women in labour, that is, in the active stage of labour in the private institutions, and exploring the opinion of midwives about what happens in the labour ward sheds light on decisions in favour of a caesarean section and divergence from the original birth plan expressed on admission. A birth plan is the anticipated way that events will take place when a baby is born, and in midwifery, many factors, including foetal distress can prevent such a birth plan (as per the wishes of the woman) from being executed.

\section{Purpose of the Study}

The purpose of this study was to explore the views of midwives regarding decision making about birthing methods in the Namibian private sector labour wards. The specific objective of the study was to determine the decision of the women about the birthing method in the private sector labour wards in Windhoek, Namibia.

\section{Research Methodology}

A qualitative exploratory descriptive design was used to determine midwives' views on birthing method decision making in the Namibian private sector labour wards in Windhoek. The qualitative approach was appropriate as it gave in-depth data on the research phenomenon. This study was exploratory, and exploratory research is often utilised when the subject under study is not well-known and when a problem needs a solution (Grove, Burns, and Gray 2013, 27). In addition, exploratory research identifies key issues to gain an understanding of a social setting (Maree 2016, 55).

\section{Research Site and Population}

Windhoek, as the research site, is the capital city of Namibia and it has an estimated population of 500000 inhabitants out of the 2510279 total population of Namibia (Waldometers 2019). Windhoek has a total of three private hospitals out of the six in the country that offer maternity services to women. 
The population for this study was an estimated 35 midwives working in the maternity units of two private hospitals in Windhoek. The third private hospital in Windhoek was excluded, as it had only been operational for six months when data collection began. Purposive sampling was adopted by focusing on midwives who had experience in the labour wards of private hospitals. Sampling continued until data saturation was achieved.

\section{Data Collection}

Semi-structured individual interviews were conducted to collect the data between March and April 2017. Pilot interviews were conducted with two midwives in one of the hospitals that participated. The data from the pilot interviews were analysed and included in the final results of the study. There were no changes made on the interview schedule following the pilot interviews.

\section{Data Analysis}

Data were analysed using the six steps of data analysis, as explained by Creswell (2014, 63). These steps included analysis of the data, preparation and organisation of data, exploration and coding of data, coding to build descriptions and themes, representing and reporting qualitative findings, interpreting findings, and validating the accuracy of findings.

\section{Ethical Considerations}

The research was approved by the Health Research Ethics Committee (HREC) at Stellenbosch University (SU) on 22 August 2016 (S16/05/097). The Namibian Ministry of Health and Social Services approved the study on 14 November 2016, and the two participating hospitals gave approval in Windhoek on 8 and 16 December 2016 respectively. Informed written consent was obtained from the research participants before the interviews, and verbal consent was obtained before the scheduled interview. Privacy was ensured in that interviews were conducted at the convenience of the research participants.

\section{Trustworthiness}

The study followed the four principles of trustworthiness in qualitative research, namely credibility, transferability, dependability and confirmability (Lincoln and Guba 1985), to ensure validity. Credibility was ensured through engagement with research participants through in-depth individual interviews. Secondly, transferability in this study was upheld through the midwives who were directly linked to the context being studied and the contextual boundaries of the findings which can be transferred to other settings in the same or different context. Thirdly, dependability was ensured through clear and detailed reporting of the research process. Last but not least, recording of the interview transcriptions of the audios, crosschecking from the co-researchers, as well as 
the use of direct quotes in the presentation of results allowed for the presence of confirmability.

\section{Research Results}

\section{Demographic Characteristics}

A total of seven female midwives took part in this research. Years of experience varied from two years to 26 years. This variability in experience created different and valuable perspectives.

The first part of the interview requested the research participants to indicate their years of experience as midwives, and their years of experience at the current workplace. The demographic responses are tabulated in Table 1 below.

Table 1: Work experience and demography

\begin{tabular}{|l|l|l|}
\hline $\begin{array}{l}\text { Pseudonym of } \\
\text { participant }\end{array}$ & $\begin{array}{l}\text { Years of experience as } \\
\text { midwife }\end{array}$ & $\begin{array}{l}\text { Years of experience at current } \\
\text { work }\end{array}$ \\
\hline P1 & 26 years & 6 years \\
\hline P2 & 6 years & Not specified \\
\hline P3 & 8 years & Not specified \\
\hline P4 & 12 years & 7 years \\
\hline P5 & 11 years & 6 years \\
\hline P6 & 4 years & 2 years \\
\hline P7 & 2 years & 2 years \\
\hline
\end{tabular}

\section{Theme 1: Woman}

- Subtheme: Antenatal care and expectations of pain management in labour

Antenatal care is a critical aspect that influences the decisions that women make in the labour wards. Some of the important factors raised by the midwives as affecting the decisions on the selection of the mode of delivery in the labour wards, included anxiety about pain (tokophobia), the "significant others" or people present during labour (inclusive of the midwife, doctor and family members), the doctor's choice, and poor progress of labour. However, midwives indicated that they would like to contribute towards informed decision making by becoming more involved antenatally. Furthermore, providing information - and thereby improving the chances of women in making informed decisions for better outcomes in the labour ward - was evidenced by the following verbatim transcriptions:

P6 "... women to have maybe one or two contact sessions with the midwives-before delivery — so that they at least have information [for] a midwife just to reinforce." 
P1 "[for] the population who has private insurance, midwives are not available, they go to a doctor, and doctors per se, are not trained to take care of women with healthy pregnancies."

Women in the labour wards have individual preferences when deciding their birthing methods and this is no exception in the Namibian context.

There is a further reflection on inadequate antenatal care and information sharing at point of entry in the system. According to the respondents, some women believe that having a caesarean section will take the pain of giving birth away immediately-thus they regard it as a "quick fix" to their agony and despair if they have been in labour for long.

P7 “... it's like they want to get rid of the pain ..."

P3 [Some women on experiencing labour pains would feel that]: “... I cannot tolerate this anymore ..."

Fear was indicated as a factor that influences decisions made in the labour wards and this relates to "fear" of the doctors when decisions were made, with the patients unconditionally accepting the doctors' decisions. This fear is driven by the idea that should the patient oppose the doctor, the doctors would then not want to take care of them. This was evidenced by some responses as indicated below:

P3 "...the doctor said it's what is best, or the doctor said—ah this baby is still not engaged ..."

P5 “... I don't know why the doctor is doing a caesarean section on me. He just said I should come to the hospital on this date for caesarean section ..."

P1 “... I also feel that mostly women ... [do] not really know what to expect, that it [labour]) can take long, and that they might require a second dose of ... medication, I think it depends a great deal how [it is] ... explained ..."

\section{Theme 2: Doctors}

- Sub-theme: Motivations for caesarean sections

Midwives raised concern over the notion that most caesarean sections are done for the convenience of the doctors, as some of the doctors attending to the pregnant women that are in labour may not want to be woken up to do a delivery at night or on a public holiday. The responses below are indicative of these views by the midwives:

P3 "I feel-some caesarean sections are done for their own [doctors'] convenience. Like they need to go for the Easter holiday, Christmas holiday, and they are having this much patients." 
P5 "But, it's just that they [doctor]) don't have patience to wait for the normal labour as it should go, maybe because they want to go somewhere, [or] they don't want to be woken up at night to come and conduct the delivery, or maybe they are scared of complications."

Shahoei et al. $(2013,304)$ concur that caesarean sections are performed for the convenience of the doctors

\section{Theme 3: Institution}

- Subtheme: Policies and guidelines

Midwives need to have a place in the facilitation of decision making of women in the labour wards so as to reduce the caesarean section rates as per comments of WHO. Midwives expressed their discontent with the status quo, and mentioned that management has to intervene in the process as indicated in the views below:

P2 "... the managers will just have to sit with the doctors and talk to them nicely because the reasons for caesarean section [are unacceptable] ... It seems now it's routine to go for a caesar - as "baby is very big." "How did you see the baby is big without trying the normal delivery?"

P3 “... our management or our immediate supervisor, if we could discuss it with them and then maybe they take it up to say that no, in maternity let the midwife also have fifty-fifty say with the doctor, pertaining to the management and the mode of delivery that is best for the women."

Policy development and implementation could help in the decisions that are made in the labour wards. When national and or institutional guidelines and policies are in place, it helps in the delivery of service. The institution has a mandate to ensure that guidelines and policies are explained and followed by all staff in the institution.

\section{Discussion}

Decision making pertaining to childbirth is crucial and it involves not only the wellbeing of the mother but also that of the infant, and ultimately the family. A study done in Sweden found that the mode of delivery does not matter to the Swedish fathers as long as the mother and baby are safe through the application of the option chosen (Johansson et al. 2014, 208). The decisions made in labour wards should be in line with the rights of childbearing women, which include informed consent (Windau-Melmer 2013,9).

Boz, Teskereci, and Akman $(2016,2)$ explain that birth partners and relatives should be included in shared decision making as this allows value-based and conscious preferences when it comes to labour and birth. Midwives in this study believe that a birth partner in the labour ward significantly encourages women in labour. The Royal 
College of Midwives concurs with the above, stating that the emotional support of the family or personnel present, who demonstrate a caring attitude towards the woman, motivates the woman in labour (Ross-Davie 2012, 4).

Tokophobia is one of the contributing factors to the high caesarean section rates as women tend to fear the pain that is associated with childbirth (Karlstrom et al. 2011, 621; Trevathan and Rosenberg 2014, 164). Literature concurs that it is an important factor during decision making in the mode of delivery (Fenwick et al. 2010, 395; Nama and Wilcock 2011, 261). However, it has also been argued that pain is subjective, and thresholds vary from one person to another.

All seven midwives that participated in this study mentioned that pain is one of the main contributors of women changing their decisions and asking for a caesarean section at the last moment, since by then their threshold for pain would have decreased significantly.

Fenwick et al. $(2010,394)$ mention that there is a comparatively high likelihood for women to have a caesarean section when they receive private care during antenatal care (and having had limited access to midwives as primary caregivers). This correlates with the present study, with midwives viewing birth as a physiological process which requires minimal if any intervention. This is opposed to the midwives' reported view of doctors, who see pathology even when it is not always the case.

The antenatal period is a critical time to provide health education, as this provides all the parties involved with a platform for a discussion of the pros and cons of a delivery method. Moreover, midwives expressed the need for women to have an encounter with midwives before they come to deliver. Literature supports the role of the midwife in the health education of women in decision making about the modes of delivery that are available to them (Boz et al. 2016, 2; Fenwick et al. 2010, 394; ICM 2014, 2).

Midwives expressed their discomfort about policies and guidelines that are present at their work places, which are not adhered to and which are interpreted very leniently. The most obvious aspect to address, according to the WHO and many scholars, is the prevention of primary caesarean sections and subsequent ones, by using vaginal birth after caesarean section in the absence of cephalo-pelvic disproportion (Childbirth Connection 2012, 3; WHO 2015a, 4).

Midwives in the private sector labour wards in Windhoek thus concur with the available literature, namely that factors such as convenience on the part of the doctors and inadequate information given, may result in fear of labour and the choice of a caesarean section. From these observations, it can be argued that the objective of the study was addressed. 


\section{Conclusion}

The findings of the study indicate that the decisions made in the labour ward are influenced by different factors, including the type of health professionals facilitating the birth process, as well as the information received prior to the onset of labour. The midwives concurred that it is important for women to receive adequate information from health professionals in order for them to make informed decisions. In addition, midwives and doctors need to coordinate health information to the women for consistency.

\section{Recommendations}

It is owed to every woman to have a memorable childbirth experience; hence policy formulations and guidelines from the Namibian Ministry of Health and Social Services to the institutions need to be women-centred, with health professionals involved equipped with adequate training and information. Both midwives and doctors need to be involved in the same information sessions, for harmonious patient management. Moreover, teamwork should be encouraged amongst the important care-givers and role players in the labour ward, with respect shown for each other's knowledge and expertise. In addition, decisions made by the doctor should be more transparent, to ensure that valid reasons for the mode of delivery are entered in the maternity register.

\section{Limitations}

The limitation of the study was that midwives were only from private hospitals, and those willing individuals who availed themselves in spite of their busy schedules

\section{Acknowledgements}

Gratitude and appreciation are expressed to Stellenbosch University Department of Nursing and Midwifery and their Ethics Committee for permission and accompaniment with the study. Secondly, the participating hospitals are thanked for allowing and availing their staff for involvement in the research study. Lastly, the midwives are thanked who participated in this study: for availing themselves and responding to the researcher to explain the problem in relation to what is, to what should be, according to the WHO.

\section{References}

“Appropriate Technology for Birth.” 1985. Lancet 24 (2) (8452): 436-437. https://doi.org/10.1016/S0140-6736(85)92750-3.

Boz, I., G. Teskereci, and G. Akman. 2016. "How Did you Choose a Mode of Birth? Experiences on Nulliparous Women from Turkey." Women and Birth 507: 1-9. https://doi.org/10.1016/j.wombi.2016.01.005. 
Brockmeyer, B. 2012. "The Health System in Namibia: Deliberations about an Affordable National Health Insurance for the Low-income Workforce in Namibia.” Accessed July 25, 2017. www.cms.my.na.

Chen, S., A. M. Hutchinson, C. Nagle, and T. K. Bucknall. 2018. "Women’s Decision Making Processes and the Influences on their Mode of Birth Following a Previous Caesarean Section in Taiwan: A Qualitative Study.” BioMed Central 18: 31. https://doi.org/10.1186/s12884-018-1661-0.

Childbirth Connection. 2012. Vaginal or Cesarean Birth: What Is at Stake for Women and Babies? New York. Childbirth Connection.

Childbirth Connection. 2014. New Cesarean Prevention Recommendations from Obstetric Leaders: What Pregnant Women Need to Know. Washington. National Partnership for Women and Families.

Coalition for Improving Maternity Services (CIMS). 2010. "The Risks of Cesarean Section.” Accessed July 21, 2015. www.motherfriendly.org.

Creswell, J. W. 2014. Research Design: Qualitative, Quantitative and Mixed Methods Approaches, 4th edition. Los Angeles: SAGE.

Fenwick, J., L. S. Midhons, D. K. Creedy, J. Gamble, and S. Bayes. 2010. "Why Do Women Request Caesarean Section in a Normal, Healthy First Pregnancy." Midwifery 26: 394400. https://doi.org/10.1016/j.midw.2008.10.011.

Gibbons, L., J. M. Belizan, J. A. Lauer, A. P. Betran, M. Merialdi, and F. Althabe. 2010. The Global Numbers and Costs of Additionally Needed and Unnecessary Caesarean Sections Performed per Year: Overuse as a Barrier to Universal Coverage. World Health Report. Geneva: WHO Publishers.

Grove, S. K., N. Burns, and J. R. Gray. 2013. The Practice of Nursing Research: Appraisal, Synthesis and Generation of Evidence. St Louise: Saunders.

International Confederation of Midwives. 2014. "Midwifery Care for Women with Complications of Childbirth." International Confederation of Midwives. Accessed July 21, 2016. www.internationalmidwives.org.

International Confederation of Midwives. 2017. "Appropriate Maternity Services for Normal Pregnacy, Childbirth and the Post Natal Period." International Confederation of Midwives. Accessed February 12, 2018. www.internationalmidwives.org.

International Federation of Gynecology and Obstetrics (FIGO). 2014. "Mother-baby Friendly Birthing Facilities.” International Journal of Gynecology and Obstetrics 128: 95-99. https://doi.org/10.1016/j.ijgo.2014.10.013. 
Johansson, M., I. Hildingsson, and J. Fenwick. 2014. “As Long as they Are Safe: Birth Mode Does not Matter: Swedish Fathers' Experience of Decision-Making around Caesarean Section." Women and Birth 27: 208-213. https://doi.org/10.1016/j.wombi.2014.03.003.

Karlstrom, A., A. Nystedt, M. Johansson, and I. Hildingsson. 2011. "Behind the Myth: Few Women Prefer Caesarean Section in the Absence of Medical or Obstetrical Factors." Midwifery 27: 620-627. https://doi.org/10.1016/j.midw.2010.05.005.

Lincoln, Y. S., and E. G. Guba. 1985. Naturalistic Inquiry. Newbury. CA: SAGE. https://doi.org/10.1016/0147-1767(85)90062-8.

Maree, K. (ed.). 2016. First Steps in Research, 2nd edition. Pretoria: Van Schaik.

Ministry of Health and Social Services. 2013. "Ministry of Health and Social Services Annual Report 2012/2013.” Windhoek: Republic of Namibia.

Nama, V., and F. Wilcock. 2011. "Ethics Caesarean Section on Maternal Request: Is Justification Necessary?" The Obstetrician and Gynaecologist 13: 263-269. https://doi.org/10.1576/toag.13.4.263.27693.

Namibia Association of Medical Aid Funds (NAMAF). 2015. Personal communication (Online), 7 May. Available e-mail: rehettai@namaf.org.na.

Ross-Davie, M. 2012. Evidence Based Guidelines for Midwifery Led Care in Labour. London: The Royal College of Midwives.

Sandall, J., R. M. Tribe, L. Avery, G. Mola, G. H. A. Visser, C. S. E. Hormer, D. Gibbons et al. 2018. "Short-term and Long-term Effects of Caesarean Sections on the Health of Women and Children." The Lancet. https://doi.org/10.1016/S0140-6736(18)31930-5.

Shahoei, R., M. Rezaei, F. Ranaei, F. Khosravy, and F. Zaheri. 2013. “Kurdish Women's Preference for Mode of Birth: A Qualitative Study." International Journal of Nursing Practice 20: 302-309. https://doi.org/10.1111/ijn.12150.

Tjihenuna, T. 2015. "Private Hospitals Over-perform C-sections.” The Namibian, 17 July: 5.

Trevathan, W. R., and K. R. Rosernberg. 2014. "Caesarean Section.” Evolution, Medicine and Public Health. https://doi.org/10.1093/emph/eou031.

Vogel, J. P., A. P. Betran, N. Vindevoghel, J. P. Souza, M. R. Torloni, J. Zhang, O. Tuncalp, R. Mori, N. Moriasaki, E. Ortiz-Panozo, B. Hernandez, R. Perez-Cuevas, Z. Qureshi, A. M. Gulmezoglu, and M. Temmerman. 2015. "Use of the Robson Classification to Assess Caesarean Section Trends in 21 Countries: A Secondary Analysis of two WHO Multicountry Surveys." Lancet 3: 260-270. https://doi.org/10.1016/S2214109X(15)70094-X.

Waldometers. 2019. "Population of Namibia." Accessed October 30, 2019. www.warldometers.info/world-population/namibia-population. 
Windau-Melmer, T. 2013. A Guide for Advocating for Respectful Maternity Care. Washington DC: Futures group. Health Policy Project.

World Health Organization (WHO). 2015a. "Caesarean Sections Should only be Performed when Medically Necessary.” Accessed April 2, 2016.

www.who.int/mediacentre/news/releases/2015/caesarean-sections/en.

World Health Organisation (WHO). 2015b. "WHO Statement On Caesarean Section Rates." Accessed April 2, 2016. www.who.int/reproductivehealth. 